\title{
Does artificial nutrition improve outcome of critical illness?
}

Miet Schetz*, Michael Paul Casaer and Greet Van den Berghe

\begin{abstract}
Nutritional support is generally considered an essential component in the management of critically ill patients. The existing guidelines advocate early enteral nutrition, with the optimal timing for the addition of parenteral nutrition to insufficient enteral feeding being the subject of transatlantic controversy. The unphysiologic intervention of artificial nutrition in critically ill patients, however, may evoke complications and side effects. Besides the classically described complications, suppression of autophagy, potentially important for cellular repair and organ recovery, was elucidated only recently. The question whether artificial nutrition in critical illness improves or worsens outcome as compared with starvation has so far not been adequately addressed. This paper provides a critical analysis of the existing literature on ICU nutrition, highlighting important methodological shortcomings of many trials and meta-analyses and underlining the urgent need for high-quality research in this field. Recent adequately designed randomized controlled trials suggest that trophic enteral feeding during the first week of critical illness is as good as full enteral feeding and that early addition of parenteral nutrition to insufficient enteral nutrition does not provide any benefit and worsens morbidity.
\end{abstract}

\section{Introduction}

Admission to the ICU is usually necessary for acute diseases/injuries or for exacerbations/complications of chronic diseases. Both are associated with variable degrees of inflammation and result in reduced energy and protein intake, increased energy expenditure and protein catabolism [1]. As a result, ICU patients - even when not malnourished prior to admission - will inevitably develop a

*Correspondence: marie.schetz@uzleuven.be

Department of Intensive Care Medicine, University Hospitals Leuven, Herestraat 49, B3000 Leuven, Belgium nutritional deficit during their ICU stay. Nutritional deficit is associated with adverse outcomes [2,3] and nutritional support is generally considered an essential part of managing ICU patients [4-6].

Existing guidelines recommend early enteral nutrition (EN) for patients who are hemodynamically stable and unable to consume a full oral diet within 3 days [4-6]. The optimal timing for adding parenteral nutrition (PN) in patients who cannot sufficiently be fed by the enteral route remains controversial, with European guidelines advocating an early start [6] whereas the American guidelines suggest postponing PN until day 7 to 10 in the absence of prior malnutrition [5]. Recommended protein requirements vary between 1.2 and $2 \mathrm{~g} / \mathrm{kg} /$ day $[5,6]$.

This paper aims to discuss the pros and cons of artificial nutrition in ICU patients and to assess the quality of the evidence for early full nutritional support in this population, with a focus on energy and protein delivery. For evaluation of evidence on micronutrients and immunonutrition, readers are referred to other recent reviews [7-11].

\section{Pros and cons of nutritional support in the ICU}

Without doubt, nutritional deficit in the ICU is associated with adverse outcomes (an association that may be causal or casual) and prolonged starvation ultimately leads to death. However, the key question is whether artificial nutrition, administered during critical illness, can prevent or correct this nutritional deficit and thereby also the associated adverse outcomes. Artificial nutrition in the critically ill is a medicine provided to anorectic patients, is unphysiologic and may evoke complications and unwanted side effects that should be weighed against any expected benefit.

Also without doubt, artificial nutrition improves energy and protein intake, but whether it also prevents accelerated muscle catabolism in immobilized critically ill patients with systemic inflammation remains unclear. The mechanisms underlying muscle atrophy and weakness in critical illness are extremely complex [12-14], and thus expecting the atrophy and weakness to be reversible by simply providing calories and protein is an oversimplification. Aggressive nutritional support in critically ill patients, 
instead of preventing muscle loss or reducing proteolysis and gluconeogenesis, merely results in fat gain [15-19].

Complications of artificial nutrition include aspiration pneumonia, feeding tube dislocation, diarrhea, abdominal hypertension, intestinal ischemia, catheter sepsis, liver steatosis, hyperglycemia, dyslipidemia and refeeding syndrome [20-22]. Nutrition also suppresses autophagy, a survival mechanism serving to recycle intracellular nutrients and maintain energy homeostasis during nutrient deprivation. Recent evidence suggests that autophagy is essential for the immune response and for housekeeping functions such as removal of toxic protein aggregates and damaged organelles, and thus it could be critical for recovery from organ failure [22-24]. A recent study of critically ill rabbits showed that early PN, especially the provision of proteins and lipids, suppressed the ubiquitin-proteasome pathway, thereby contributing to the preservation of muscle mass, but also evoked a phenotype of autophagy deficiency in liver and skeletal muscle, suggesting that the maintenance of muscle mass might come at the price of accumulation of toxic protein aggregates, thus compromising function [25]. This same phenotype has also been found in the liver and muscle of fed critically ill patients [26] and was recently shown to contribute to vital organ failure in an animal model of critical illness [27]. Autophagy-deficient mice show muscle loss with accumulation of toxic proteins and dysfunctional organelles [28,29], suggesting that nutrition-induced suppression of autophagy might even have a negative impact on fat-free mass.

A direct link between nutrition and organ failure was also shown in a series of animal experiments evaluating the impact of different nutritional regimen on ischemiareperfusion injury in the kidney. In these experiments, nutrition - more specifically protein rather than glucose appears to increase the extent of kidney injury [30-32].

Given these pros and cons of artificial nutrition in critical illness, clinical trials should have clinical (morbidity, mortality, long-term functional outcome) and not nutritional or other surrogate endpoints. Also surprising is that the majority of the existing literature concentrates on when, how and what to feed, whereas the beneficial effect of feeding per se is rarely questioned.

\section{What is the evidence that (more) nutrition improves outcome? \\ Observational trials}

Several observational trials (OTs) suggest an association between caloric deficit and adverse outcomes. This caloric deficit mainly develops during the first days in the ICU, when EN is insufficient due to hemodynamic instability, slow progression to target, poor tolerance (gastric retention/vomiting) and interruptions for procedures $[33,34]$. In a large multinational prospective OT, an inverse relationship between caloric input and risk of mortality was only significant for patients with body mass index $<25$ or $>35 \mathrm{~kg} / \mathrm{m}^{2}$ [35]. In another OT, proteins and energy were titrated separately for patients with an expected prolonged ICU stay. The authors concluded that achieving the energy/protein target is associated with lower 28-day mortality. However, ICU and hospital mortalities showed an opposite trend (surprisingly translated into a hazard ratio $<1$ in the unadjusted Cox proportional hazard analysis, suggesting erroneous censoring as discussed below). ICU and hospital stays and duration of mechanical ventilation were shortest for patients reaching neither the energy target nor the protein target [36]. In other OTs, higher caloric intake was associated with poorer outcomes, including mortality and infections $[37,38]$.

Early initiation of (mainly enteral) nutrition was associated with a lower mortality in several OTs $[39,40]$. However the incidence of ventilator-associated pneumonia was lower and the ICU stay was shorter in the late initiation group [39]. Another OT found more gastrointestinal complications and a longer ICU stay with early initiation of EN in patients with high illness severity [41]. Early addition of PN to insufficient EN was not associated with shorter hospital stay in another large OT $[42,43]$.

The evidence for the recommended amount of protein in artificial nutrition is limited. Four OTs using isotopes $[44,45]$, nitrogen balances [46] or measurements of body composition [47] in an aggregate total of 90 septic, trauma or burn patients have shown that the net balance between protein synthesis and protein breakdown is improved with protein intakes up to 1 to $1.5 \mathrm{~g} / \mathrm{kg} /$ day, whereas any further increase in protein intake is wasted in oxidative pathways. However, there are no randomized controlled trials (RCTs) showing any benefit of more protein intake on clinically relevant outcomes.

A major methodological problem with OTs investigating ICU nutrition is confounding by indication. Patients who receive less or later feeding also have an explanatory reason why feeding is inadequate or delayed, which is mainly related to illness severity. In addition, association is never proof of causality. True evidence for the optimal amount, route and timing of nutritional support in critically ill patients can hence only be provided by RCTs.

Another methodological (statistical) issue that often results in incorrect interpretation of clinical trials is inappropriate censoring $[48,49]$ for any type of time-toevent survival analysis (for example, Kaplan-Meier statistics or Cox proportional hazards models) when the duration of follow-up is not identical for all subjects. To illustrate this problem we refer to the trial evaluating the impact of reaching nutritional targets on survival [36], where patients were followed-up throughout their hospital stay. Patients reaching the nutritional target had 
longer ICU and hospital stays and also numerically higher ICU and hospital mortalities. However, uncorrected Cox proportional hazard analysis, censoring patients at last follow-up, suggested a lower mortality risk for patients reaching target. These data are internally inconsistent and can only be explained by inappropriate use of informative censoring.

Censoring is informative when the reason why a patient is censored (no longer included in the analysis) is not just by chance but in fact related to the outcome $[48,49]$. In the above-mentioned study, patients discharged earlier (and subsequently omitted from the analysis) do not have the same mortality risk as those who remain in the ICU or hospital [36]. The deletion/censoring of early discharge patients lowers the number of patients at risk (the denominator in the calculation) in the cohort not reaching nutritional target and, as a result, for a similar or lower numerical mortality, the proportion (altered by the lower denominator) of patients dying in that cohort seems higher (see illustration in Figure 1). This problem is preventable by obtaining landmark time-to-event analysis (for example, 90-day mortality) in all patients. Conversely, if the duration of stay in the ICU or hospital is the endpoint, patients dying before ICU/hospital discharge should be censored after the last patient has been discharged alive, to account for such competing risk between length of stay and mortality [50].

\section{Meta-analyses of older randomized controlled trials}

RCTs that compare any form or amount of (enteral or parenteral) nutrition with tolerating starvation (withholding/delaying nutritional support) in critically ill patients are non-existent [51]. Results from older (all largely underpowered) RCTs on other aspects of ICU nutrition have been summarized in meta-analyses, many of them including elective surgery patients. Two recent meta-analyses, limited to critically ill patients, showed a significant reduction of infections with early EN compared with late EN, whereas mortality reached significance in only one of the trials $[52,53]$. The quality of the included trials was poor, however, with high risk of bias [54-56]. Meta-analyses comparing EN with PN in critically ill patients suggested a reduction of infectious complications with EN but the mortality results were conflicting $[57,58]$. In many of the included RCTs, PN patients received more calories and had higher blood glucose levels than EN patients. Finally, two metaanalyses of trials comparing EN with a combination of $\mathrm{PN}$ and EN did not establish clinical benefit [58,59].

A common problem with all these meta-analyses is that they included small, old studies with high risk of bias (for example, lack of randomization concealment, no blinded outcome assessment, no intention-to-treat analysis). Other problems are the inclusion of different patient populations with variable illness severity and baseline nutritional status, variable nutritional formulations, inconsistent definitions of early, widely varying caloric input, and so forth. Better quality research on ICU nutrition is therefore urgently needed.

\section{Recent randomized controlled trials}

Two recent RCTs have compared different amounts of EN in ICU patients $[60,61]$. The first single-center trial compared the provision of 90 to $100 \%$ of the caloric goal with permissive underfeeding, defined as 60 to $70 \%$ of the target in 240 (of 1,587 screened) patients receiving EN and expected to remain in the ICU for at least 48 hours [60]. Permissive underfeeding significantly reduced the hospital mortality (risk ratio $=0.71 ; 95 \%$ confidence interval $=0.50$ to 0.99$)$ and tended to reduce 180-day mortality (risk ratio $=0.74 ; 95 \%$ confidence interval $=$ 0.53 to 1.03$)$. However, the actual energy delivery only differed by $10 \%$ ( $59 \%$ vs. $71 \%$ of target) [60]. The small number of patients, without a well-motivated sample size calculation to guarantee the required statistical power, makes this trial prone to observations evoked by chance.

The EDEN trial is a multicenter open-label RCT comparing trophic EN with full EN in 1,000 (of 7,968 screened) adult patients with acute lung injury requiring mechanical ventilation [61]. The sample size of this trial was determined by a well-rationalized calculation. In the full feeding group, EN was advanced to goal (25 to $30 \mathrm{kcal} / \mathrm{kg}$ ideal body weight/day of nonprotein calories) as quickly as possible. Patients in the trophic feeding group received $20 \mathrm{kcal} / \mathrm{hour}$, and advanced to full feeding only if they were still on mechanical ventilation after 6 days. The actual caloric intake was $400 \mathrm{kcal} /$ day $(25 \%$ of target) for trophic EN versus $1,300 \mathrm{kcal} /$ day $(80 \%$ of target) for full EN. The feeding protocol had no significant effect on ventilator-free days through 28 days (the primary endpoint), nor on infectious complications, ICU-free days, organ failure-free days or 60-day mortality. Patients in the full-feeding group had significantly more episodes of gastrointestinal intolerance, higher blood glucose levels and insulin requirement and a greater cumulative net fluid balance [61]. An important limitation of this trial is the high exclusion rate, mainly for high disease severity or important comorbidity, thus limiting the generalizability of its findings.

Taken together, these two RCTs suggest that limiting enteral caloric delivery during the first ICU days is not deleterious for clinical outcome. Potential limitations are the insufficient power to prove equivalence between the nutritional strategies, the absence of prior malnutrition in included patients and the lack of long-term functional outcomes [62].

Two other RCTs evaluated the concept of combined PN and EN to prevent the development of a caloric 

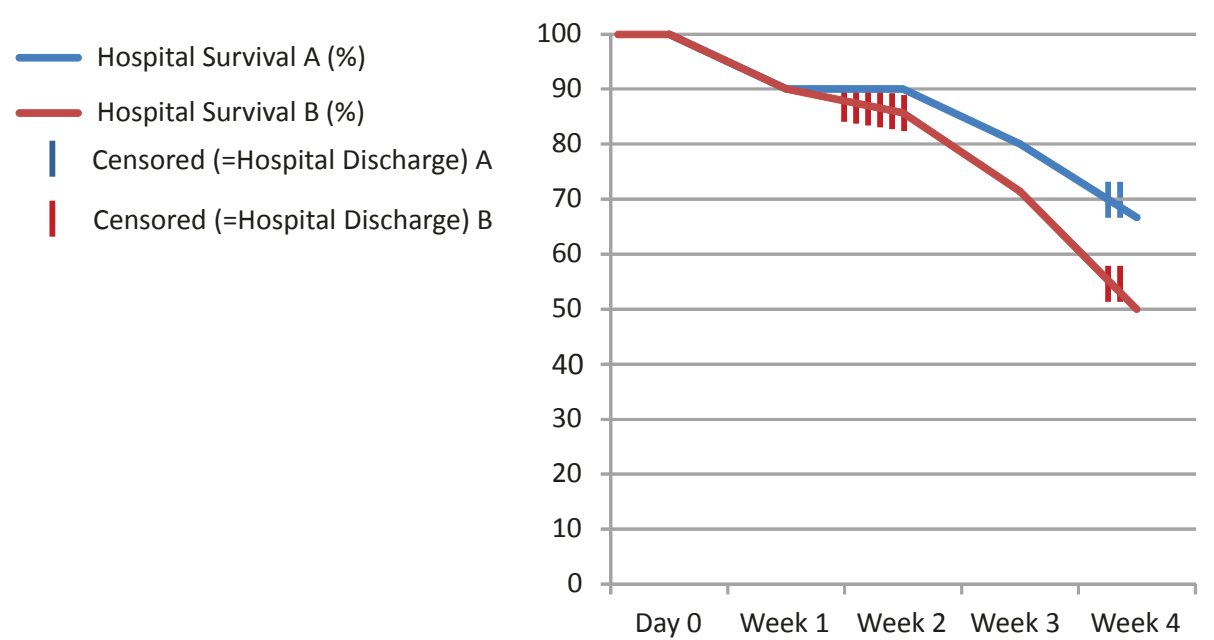

\begin{tabular}{|l|l|c|c|c|c|c|c|}
\hline & & Day 0 & Week 1 & Week 2 & Week 3 & Week 4 \\
\hline \multirow{4}{*}{ Group A } & Died (n) & 0 & 2 & 0 & 2 & 2 \\
\cline { 2 - 7 } & Discharged (n) & 0 & 0 & 0 & 0 & 2 \\
\cline { 2 - 7 } & Hospital Survivors (n) & 20 & 18 & 18 & 16 & 12 \\
\cline { 2 - 7 } & Observed population (n) & 20 & 20 & 20 & 20 & 18 \\
\cline { 2 - 7 } & Hospital Survival A (\%) & 100 & 90 & 90 & 80 & 67 \\
\hline \multirow{5}{*}{ Group B } & Died (n) & 0 & 2 & 0 & 2 & 2 \\
\cline { 2 - 7 } & Discharged (n) & 0 & 0 & 6 & 0 & 2 \\
\cline { 2 - 7 } & Hospital Survivors (n) & 20 & 18 & 12 & 10 & 6 \\
\cline { 2 - 7 } & Observed population (n) & 20 & 20 & 14 & 14 & 12 \\
\cline { 2 - 7 } & Hospital Survival B (\%) & 100 & 90 & 86 & 71 & 50 \\
\hline
\end{tabular}

Figure 1. Informative censoring in two patient groups with identical hospital mortality but different hospital stay duration. Group $A$ and B have identical hospital mortalities (6/20) but hospital stay in group B is shorter. Kaplan-Meier curves wrongly estimate a lower survival in group B; proportional hazard ratios will be affected likewise.

deficit [63,64]. The Tight Calorie Control Study (TICACOS) was conceived as a pilot trial and hence no sample size calculation was performed. This trial included $130 \mathrm{ICU}$ (of 944 screened) patients on mechanical ventilation with an expected ICU stay $\geq 3$ days [63]. Within 48 hours after admission, patients were randomized to the tight-calorie group, in which caloric intake was adjusted daily under supervision of a dietician guided by repeated indirect calorimetry, or a control group receiving a fixed $25 \mathrm{kcal} / \mathrm{kg} /$ day. If the caloric target could not be reached by EN alone, PN was added. In the tight-calorie group, the measured target varied significantly over time and caloric intake exceeded this target, resulting in a cumulative energy balance of $2,008 \pm 2,177 \mathrm{kcal}$. Three patients received exclusive PN and 19 patients received combined PN and EN. In the control group, intake was consistently below the calculated target, resulting in a cumulative energy balance of $-3,550 \pm 4,591 \mathrm{kcal}$. Only one patient received exclusive PN and seven patients received combined EN and PN. The results for hospital mortality, the primary outcome, are only given for the per-protocol analysis (28.5\% vs. $48.2 \% ; P=0.023$ in favor of the tight-calorie group). The survival curve revealed a trend for decreased mortality in the intention-to-treat analysis and a significantly decreased mortality in the per-protocol analysis. However, both ICU and hospital stays were shorter in the tight-calorie group, clearly introducing the statistical problem of informative censoring/competing risk that we discussed earlier. In addition, not only the ICU stay but also the duration of mechanical ventilation was significantly longer in the tight-calorie group, which also revealed more infectious complications. The design of the study also does not allow distinguishing effects of indirect calorimetry guidance versus providing more nutrition [63]. A multicenter trial with similar design is currently ongoing (clinicaltrials.gov: NCT01479673).

The Early Parenteral Nutrition Completing Insufficient Enteral Nutrition in Adult ICU Patients (EPaNIC) trial is the largest RCT in the field of ICU nutrition. This trial randomized 4,640 ICU (of 8,703 screened) patients with nutritional risk score $\geq 3$ to either early or late initiation of PN to complete insufficient EN [64]. Patients with severe prior malnutrition (body mass index $<17 \mathrm{~kg} / \mathrm{m}^{2} ; n=106$ ) were excluded. Patients in both groups received EN according to a standardized protocol. Calculations of 
caloric target included protein energy and were based on age, gender and ideal body weight ( 25 to $35 \mathrm{kcal} / \mathrm{kg} /$ day). On days 1 and 2, the early PN group received 20\% glucose to reach the caloric goal of 400 and $800 \mathrm{kcal} /$ day, respectively. Mixed PN was started on day 3 and was continued until $80 \%$ of the caloric target was met by EN or the restart of oral feeding. The late PN group received glucose $5 \%$ in addition to EN for the first week in the ICU. If EN was insufficient after day $7, \mathrm{PN}$ was added to achieve the target. Trace elements, minerals and micronutrients were given to both groups from day 3 onwards until full EN was reached. The EN amount did not differ between groups and reached $\pm 50 \%$ of target at day 7 . The early PN group received significantly more calories and proteins during the first 7 days. The ICU, hospital and 90-day survival rates (safety outcomes) were comparable. The ICU stay (primary outcome) was significantly shorter in the late PN group, reflected in a $6.3 \%$ increase in the likelihood of being discharged alive earlier from the ICU with a hazard ratio of 1.06 (95\% confidence interval 1.0 to 1.13). The late PN group also had a shorter hospital stay, fewer new infections (22.8\% vs. $26.2 \%)$ and a shorter duration of mechanical ventilation. Functional status at hospital discharge (evaluated in $\pm 2,000$ patients) was not affected by randomization. Late $\mathrm{PN}$ reduced total billed healthcare costs by $€ 1,110 /$ patient.

Of particular interest was the subgroup of 517 patients with contraindications for EN. In this subgroup the beneficial effect of withholding early $\mathrm{PN}$, and thus tolerating virtual fasting for 1 week, was even more pronounced. Whether this reflects benefit of withholding any nutrition, irrespective of the route, or more deleterious effects of more PN remains to be studied [64]. The EPaNIC trial is unique by its power, preplanned analysis of hard clinical endpoints and blinding of outcome assessors. Formulated criticisms include the inclusion of a large postcardiac surgery cohort, although showing a similar outcome, and the use of tight glycemic control. Tolerating more PN-induced hyperglycemia, however, is very unlikely to improve outcome with early PN.

In summary, both the TICACOS trial and the EPaNIC trial show a beneficial effect of reduced energy intake on morbidity. The difference with regard to survival outcome in these trials with markedly different inclusion criteria (the TICACOS trial only included a small and specific subset of ICU patients, whereas the EPaNIC trial included a very representative sample of all-comers in the ICU) requires further investigation.

\section{Conclusion}

The provision of artificial nutrition to critically ill patients is largely based on association between malnutrition and poor outcome. Whether and to what extent artificial nutrition can prevent/attenuate muscle wasting/weakness or accelerate recovery, however, remains unclear. In addition, artificial nutrition during critical illness has deleterious effects that should be weighed against any presumed benefit. Future clinical trials should include hard clinical endpoints.

The available evidence suggests that, in patients without severe prior malnutrition, early trophic enteral feeding is at least as good as full EN and that early addition of $\mathrm{PN}$ to insufficient $\mathrm{EN}$ does not provide any benefit and worsens morbidity. How long critically ill patients can be nutrient restricted or how to determine at which time point the benefits of artificial nutrition start to outweigh the risks remains to be determined.

\section{Abbreviations}

EN, enteral nutrition; EPaNIC, Early Parenteral Nutrition Completing Insufficient Enteral Nutrition in Adult ICU Patients; OT, observational trial; PN, parenteral nutrition; RCT, randomized controlled trial; TICACOS, Tight Calorie Control Study.

\section{Competing interests}

Baxter Healthcare provided an unrestricted research grant to KU Leuven that covered less than a third of the costs of the EPaNIC trial.

\section{Published: 1 February 2012}

\section{References}

1. Jensen GL, Mirtallo J, Campher C, Dhaliwal R, Forbes A, Grijalba RF, Hardy G, Kondrup J, Labadarios D, Nyulasi I, Castillo Pineda JC, Waitzberg D; International Consensus Guideline Committee: Adult starvation and disease-related malnutrition: a proposal for etiology-based diagnosis in the clinical practice setting from the International Consensus Guideline Committee. J Parenter Enteral Nutr 2010, 34:156-159.

2. Correia MI, Waitzberg DL: The impact of malnutrition on morbidity, mortality, length of hospital stay and costs evaluated through a multivariate model analysis. Clin Nutr 2003, 22:235-239.

3. Lim SL, Ong KC, Chan YH, Loke WC, Ferguson M, Daniels L: Malnutrition and its impact on cost of hospitalization, length of stay, readmission and 3-year mortality. Clin Nutr 2012, 31:345-350.

4. Kreymann KG, Berger MM, Deutz NE, Hiesmayr M, Jolliet P, Kazandjiev G, Nitenberg G, Van den BG, Wernerman J, Ebner C, Hartl W, Heymann C, Spies C: ESPEN guidelines on enteral nutrition: intensive care. Clin Nutr 2006, 25:210-223.

5. McClave SA, Martindale RG, Vanek VW, McCarthy M, Roberts P, Taylor B, Ochoa JB, Napolitano L, Cresci G; A.S.P.E.N. Board of Directors, American College of Critical Care Medicine, Society of Critical Care Medicine: Guidelines for the provision and assessment of nutrition support therapy in the adult critically ill patient: Society of Critical Care Medicine (SCCM) and American Society for Parenteral and Enteral Nutrition (A.S.P.E.N.). J Parenter Enteral Nutr 2009, 33:277-316.

6. Singer P, Berger MM, Van den Berghe G, Biolo G, Calder P, Forbes A, Griffiths R, Kreyman G, Leverve $X$, Pichard C; ESPEN: ESPEN quidelines on parenteral nutrition: intensive care. Clin Nutr 2009, 28:387-400.

7. Manzanares W, Dhaliwal R, Jiang X, Murch L, Heyland DK: Antioxidant micronutrients in the critically ill: a systematic review and meta-analysis. Crit Care 2012, 16:R66.

8. Visser J, Labadarios D, Blaauw R: Micronutrient supplementation for critically ill adults: a systematic review and meta-analysis. Nutrition 2011, 27:745-758.

9. Vanek WW, Matarese LE, Robinson M, Sacks GS, Young LS, Kochevar M; Novel Nutrient Task Force, Parenteral Glutamine Workgroup, American Society for Parenteral and Enteral Nutrition (A.S.P.E.N.) Board of Directors: A.S.P.E.N. position paper: parenteral nutrition glutamine supplementation. Nutr Clin Pract 2011, 26:479-494

10. Mizock BA: Immunonutrition and critical illness: an update. Nutrition 2010 26:701-707 
11. Wischmeyer P: Nutritional pharmacology in surgery and critical care:'you must unlearn what you have learned'. Curr Opin Anaesthesiol 2011, 24:381-388.

12. Sandri M: Signaling in muscle atrophy and hypertrophy. Physiology (Bethesda) 2008, 23:160-170.

13. Llano-Diez M, Gustafson AM, Olsson C, Goransson H, Larsson L: Muscle wasting and the temporal gene expression pattern in a novel rat intensive care unit model. BMC Genomics 2011, 12:602.

14. Derde S, Hermans G, Derese I, Güiza F, Hedström Y, Wouters PJ, Bruyninckx F, D'Hoore A, Larsson L, Van den Berghe G, Vanhorebeek I: Muscle atrophy and preferential loss of myosin in prolonged critically ill patients. Crit Care Med 2012, 40:79-89.

15. Streat SJ, Beddoe AH, Hill GL: Aggressive nutritional support does not prevent protein loss despite fat gain in septic intensive care patients. J Trauma 1987, 27:262-266.

16. Frankenfield DC, Smith JS, Cooney RN: Accelerated nitrogen loss after traumatic injury is not attenuated by achievement of energy balance. J Parenter Enteral Nutr 1997, 21:324-329.

17. Hart DW, Wolf SE, Herndon DN, Chinkes DL, Lal SO, Obeng MK, Beauford RB, Mlcak RT RP: Energy expenditure and caloric balance after burn: increased feeding leads to fat rather than lean mass accretion. Ann Surg 2002, 235:152-161.

18. Tappy L, Berger M, Schwarz JM, McCamish M, Revelly JP, Schneiter P, Jéquier E, Chioléro R: Hepatic and peripheral glucose metabolism in intensive care patients receiving continuous high- or low-carbohydrate enteral nutrition. J Parenter Enteral Nutr 1999, 23:260-267.

19. Schwarz JM, Chioléro R, Revelly JP, Cayeux $C$, Schneiter $P$, Jéquier $E$, Chen $T$, Tappy L: Effects of enteral carbohydrates on de novo lipogenesis in critically ill patients. Am J Clin Nutr 2000, 72:940-945.

20. Hiesmayr M: Nutrition risk assessment in the ICU. Curr Opin Clin Nutr Metab Care 2012, 15:174-180

21. Ziegler TR: Parenteral nutrition in the critically ill. N Engl J Med 2009, 361:1088-1097.

22. Moreau K, Luo S, Rubinsztein DC: Cytoprotective roles for autophagy. Curr Opin Cell Biol 2010, 22:206-211.

23. Mizushima N, Komatsu M: Autophagy: renovation of cells and tissues. Cell 2011, 147:728-741.

24. Cuervo AM, Macian F: Autophagy, nutrition and immunology. Mol Aspects Med 2012, 33:2-13

25. Derde S, Vanhorebeek I, Güiza F, Derese I, Gunst J, Fahrenkrog B, Martinet W, Vervenne H, Ververs EJ, Larsson L, Van den Berghe G: Early parenteral nutrition evokes a phenotype of autophagy deficiency in liver and skeletal muscle of critically ill rabbits. Endocrinology 2012, 153:267-276.

26. Vanhorebeek I, Gunst J, Derde S, Derese I, Boussemaere M, Güiza F, Martinet W, Timmermans JP, D'Hoore A, Wouters PJ, Van den Berghe G: Insufficient activation of autophagy allows cellular damage to accumulate in critically ill patients. J Clin Endocrinol Metab 2011, 96:E633-E645.

27. Gunst J, Derese I, Aertgeerts A, Ververs EJ, Wauters A, Van den Berghe G, Vanhorebeek I:. Insufficient autophagy contributes to mitochondrial dysfunction, organ failure and adverse outcome in an animal model of critical illness. Crit Care Med 2012, in press.

28. Masiero E, Sandri M: Autophagy inhibition induces atrophy and myopathy in adult skeletal muscles. Autophagy 2010, 6:307-309.

29. Masiero E, Agatea L, Mammucari C, Blaauw B, Loro E, Komatsu M, Metzger D, Reggiani $C$, Schiaffino S, Sandri M: Autophagy is required to maintain muscle mass. Cell Metab 2009, 10:507-515.

30. Mitchell JR, Verweij M, Brand K, van de Ven M, Goemaere N, van den Engel S, Chu T, Forrer F, Müller C, de Jong M, van IJcken W, IJzermans JN, Hoeijmakers $J$, de Bruin RW: Short-term dietary restriction and fasting precondition against ischemia reperfusion injury in mice. Aging Cell 2010, 9:40-53.

31. Verweij $M$, van de Ven M, Mitchell JR, van den Engel S, Hoeijmakers JH, ljzermans JN, de Bruin RW: Glucose supplementation does not interfere with fasting-induced protection against renal ischemia/reperfusion injury in mice. Transplantation 2011, 92:752-758.

32. Peng W, Robertson L, Gallinetti J, Mejia P, Vose S, Charlip A, Chu T, Mitchell JR: Surgical stress resistance induced by single amino acid deprivation requires Gcn2 in mice. Sci Trans/ Med 2012, 4:118ra11.

33. Dvir D, Cohen J, Singer P: Computerized energy balance and complications in critically ill patients: an observational study. Clin Nutr 2006, 25:37-44.

34. Villet S, Chiolero RL, Bollmann MD, Revelly JP, Cayeux R N MC, Delarue J, Berger MM: Negative impact of hypocaloric feeding and energy balance on clinical outcome in ICU patients. Clin Nutr 2005, 24:502-509.

35. Alberda C, Gramlich L, Jones N, Jeejeebhoy K, Day AG, Dhaliwal R, Heyland DK: The relationship between nutritional intake and clinical outcomes in critically ill patients: results of an international multicenter observational study. Intensive Care Med 2009, 35:1728-1737.

36. Weijs PJ, Stapel SN, de Groot SD, Driessen RH, de Jong E, Girbes AR, Strack van Schijndel RJ, Beishuizen A: Optimal protein and energy nutrition decreases mortality in mechanically ventilated, critically ill patients: a prospective observational cohort study. J Parenter Enteral Nutr 2012, 36:60-68.

37. Krishnan JA, Parce PB, Martinez A, Diette GB, Brower RG: Caloric intake in medical ICU patients: consistency of care with guidelines and relationship to clinical outcomes. Chest 2003, 124:297-305.

38. Arabi YM, Haddad SH, Tamim HM, Rishu AH, Sakkijha MH, Kahoul SH, Britts RJ: Near-target caloric intake in critically ill medical-surgical patients is associated with adverse outcomes. J Parenter Enteral Nutr 2010, 34:280-288.

39. Artinian $\mathrm{V}$, Krayem $\mathrm{H}$, DiGiovine $B$ : Effects of early enteral feeding on the outcome of critically ill mechanically ventilated medical patients. Chest 2006, 129:960-967.

40. Khalid I, Doshi P, DiGiovine B: Early enteral nutrition and outcomes of critically ill patients treated with vasopressors and mechanical ventilation. Am J Crit Care 2010, 19:261-268.

41. Huang HH, Hsu CW, Kang SP, Liu MY, Chang SJ: Association between illness severity and timing of initial enteral feeding in critically ill patients: a retrospective observational study. Nutr J 2012, 11:30.

42. Kutsogiannis J, Alberda C, Gramlich L, Cahill NE, Wang M, Day AG, Dhaliwal R, Heyland DK: Early use of supplemental parenteral nutrition in critically ill patients: results of an international multicenter observational study. Crit Care Med 2011, 39:2691-2699

43. Cahill NE, Murch L, Jeejeebhoy K, McClave SA, Day AG, Wang M, Heyland DK: When early enteral feeding is not possible in critically ill patients: results of a multicenter observational study. J Parenter Enteral Nutr 2011, 35:160-168.

44. Wolfe RR, Goodenough RD, Burke JF, Wolfe MH: Response of protein and urea kinetics in burn patients to different levels of protein intake. Ann Surg 1983, 197:163-171.

45. Shaw JH, Wildbore M, Wolfe RR: Whole body protein kinetics in severely septic patients. The response to glucose infusion and total parenteral nutrition. Ann Surg 1987, 205:288-294.

46. Larsson J, Lennmarken C, Mårtensson J, Sandstedt S, Vinnars E: Nitrogen requirements in severely injured patients. Br J Surg 1990, 77:413-416.

47. Ishibashi N, Plank LD, Sando K, Hill GL: Optimal protein requirements during the first 2 weeks after the onset of critical illness. Crit Care Med 1998, 26:1529-1535

48. Leung KM, Elashoff RM, Afifi AA: Censoring issues in survival analysis. Annu Rev Public Health 1997, 18:83-104.

49. Peduzzi P, Henderson W, Hartigan P, Lavori P: Analysis of randomized trials. Epidemiol Rev 2002, 24:26-38.

50. Casaer MP, Hermans G, Wilmer A, Van den Berghe G: Impact of early parenteral nutrition completing enteral nutrition in adult critically ill patients (EPaNIC trial): a study protocol and statistical analysis plan for a randomized controlled trial. Trials 2011, 12:21.

51. Ziegler TR: Nutrition support in critical illness - bridging the evidence gap. NEngl J Med 2011, 365:562-564.

52. Doig GS, Heighes PT, Simpson F, Sweetman EA, Davies AR: Early enteral nutrition, provided within $24 \mathrm{~h}$ of injury or intensive care unit admission, significantly reduces mortality in critically ill patients: a meta-analysis of randomised controlled trials. Intensive Care Med 2009, 35:2018-2027.

53. McClave SA, Heyland DK: The physiologic response and associated clinical benefits from provision of early enteral nutrition. Nutr Clin Pract 2009, 24:305-315.

54. Koretz RL, Avenell A, Lipman TO, Braunschweig CL, Milne AC: Does enteral nutrition affect clinical outcome? A systematic review of the randomized trials. Am J Gastroentero/ 2007, 102:412-429.

55. Koretz RL: Enteral nutrition: a hard look at some soft evidence. Nutr Clin Pract 2009, 24:316-324

56. Doig GS, Simpson F, Sweetman EA: Evidence-based nutrition support in the intensive care unit: an update on reported trial quality. Curr Opin Clin Nutr Metab Care 2009, 12:201-206.

57. Simpson F, Doig GS: Parenteral vs. enteral nutrition in the critically ill patient: a meta-analysis of trials using the intention to treat principle. Intensive Care Med 2005, 31:12-23. 
58. Critical Care Nutrition [http://www.criticalcarenutrition.com]

59. Dhaliwal R, Jurewitsch B, Harrietha D, Heyland DK: Combination enteral and parenteral nutrition in critically ill patients: harmful or beneficial? A systematic review of the evidence. Intensive Care Med 2004, 30:1666-1671.

60. Arabi YM, Tamim HM, Dhar GS, Al-Dawood A, Al-Sultan M, Sakkijha MH, Kahoul SH, Brits R: Permissive underfeeding and intensive insulin therapy in critically ill patients: a randomized controlled trial. Am J Clin Nutr 2011, 93:569-577.

61. National Heart, Lung, and Blood Institute Acute Respiratory Distress Syndrome (ARDS) Clinical Trials Network; Rice TW, Wheeler AP, Thompson BT, Steingrub J, Hite RD, Moss M, Morris A, Dong N, Rock P: Initial trophic vs full enteral feeding in patients with acute lung injury: the EDEN randomized trial. JAMA 2012, 307:795-803

62. Griffiths RD: Nutrition for critically ill patients: how much is enough? JAMA 2012, 307:845-846.
63. Singer P, Anbar R, Cohen J, Shapiro H, Shalita-Chesner M, Lev S, Grozovski E, Theilla M, Frishman S, Madar Z: The tight calorie control study (TICACOS): a prospective, randomized, controlled pilot study of nutritional support in critically ill patients. Intensive Care Med 2011, 37:601-609.

64. Casaer MP, Mesotten D, Hermans G, Wouters PJ, Schetz M, Meyfroidt G, Van Cromphaut S, Ingels C, Meersseman P, Muller J, Vlasselaers D, Debaveye Y, Desmet L, Dubois J, Van Assche A, Vanderheyden S, Wilmer A, Van den Berghe G: Early versus late parenteral nutrition in critically ill adults. N Engl J Med 2011, 365:506-517.

doi:10.1186/cc11828

Cite this article as: Schetz $M$, et al:: Does artificial nutrition improve outcome of critical illness? Critical Care 2013, 17:302 